\title{
Three Cases of Calcifying Pseudoneoplasm which Involve the Epidural Space of the Spine
}

\author{
Seung Yoon Song, Seong Yeol Ahn, Jong Joo Rhee, Jong Won Lee, \\ Jin Woo Hur, Hyun Koo Lee \\ Department of Neurosurgery, Cheong-ju St. Mary's Hospitial, Chungbuk, Korea
}

Calcifying psuedoneoplasm of the spine is a rare non-neoplastic lesion of unknown origin. Radiologic and histologic manifestations are very variable and clinical symptoms include isolated pain, myelopathy, and radiculopathy. Surgical resection is the preferred option of treatment. This report describes three cases of calcifying pseudoneoplasm in the spine. The first case is a 77-year-old female with pain in both legs. The second case is a 67-year-old woman who presented as right leg pain. The third case is a 78-year-old woman with isolated back pain. The involved sites of each of cases were T12, L2-3, and L1, respectively. Surgical resection of the involved masses relieved symptoms.

Key Words: Calcifying pseudoneoplasm • Epidural $\cdot$ Spine

\section{INTRODUCTION}

Calcifying psuedoneoplasm (CPN) involving the neural axis is very rare, with spinal involvement being even less frequent. About 20 cases of spinal CPN have been reported since the first description in $1978^{16}$. The symptoms of spinal CPN vary from asymptomatic lesion to isolated pain, radiculopathy, or myelopathy. Lesions display, varied findings on imaging that can lead to erroneous malignant and inflammatory differential diagnoses. The pathogenesis of this non-neoplastic lesion is not obvious. Most cases are treated by surgical resection with good outcomes.

We present three cases of epidural CPN and review imaging and pathologic characteristics, surgical management, and outcomes. We also discuss the pathogenesis of epidural CPN.

\section{CASE REPORT}

\section{Case 1}

A 77-year-old woman presented with more than a two-year

- Received: August 12, 2015 - Revised: September 10, 2015

- Accepted: September 10, 2015

Corresponding Author: Jong Joo Rhee, MD, PhD

Department of Neurosurgery, Cheong-ju St. Mary's Hospitial, 173-19, Juseong-ro, Cheongwon-gu, Cheongju-si, Chungbuk 28323, Korea

Tel: +82-43-219-8000, Fax: +82-43-291-8112

E-mail: medpia@hanmail.net

@This is an Open Access article distributed under the terms of the Creative Commons Attribution Non-Commercial License (http://creativecommons.org/ licenses/by-nc/3.0/) which permits unrestricted non-commercial use, distribution, and reproduction in any medium, provided the original work is properly cited. history of low back pain and pain in both legs, especially the left leg. Pain had become more aggravated following a minor trauma 20 days previously. She had a history for operation of vertebroplasty at the L1 body due to osteoporotic compression fracture 8 years ago. Computed tomography (CT) scans of the thoracolumbar spine showed three nodular high density lesions or structures in both anterolateral epidural space at the T12 body (Fig. 1A). Magnetic resonance imaging (MRI) showed three nodular dark T1 and T2 signal intensity lesions in the anterolateral epidural space at T12 body with thecal sac compression (Fig. 1B, C). After laminectomy of T12, gross total resections of masses were done. The masses were firm and adherent to the dura mater. Histologically, epitheloid cells in a granuloma-like pattern, fibrocellular stroma with spindled fibroblastic cells, and calcified materials were found. These pathology findings confirmed a CPN (Fig. 2). Postoperatively, back pain and radicular pain were resolved. Follow-up CT
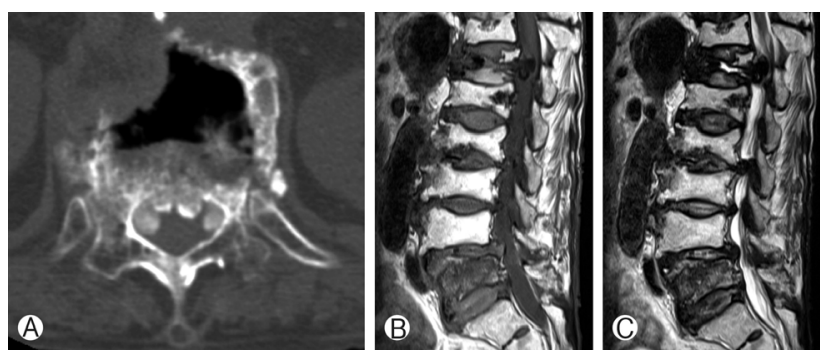

Fig. 1. Non-enhancing spinal computed tomography shows three hyperdense masses of the anterior spinal cord (A). Sagittal T1weighted $(B)$ and T2-weighted $(C)$ magnetic resonance imaging show hypointense masses in the anterior epidural space at vertebra T12 level.

Copyright (C) 2015 The Korean Spinal Neurosurgery Society 


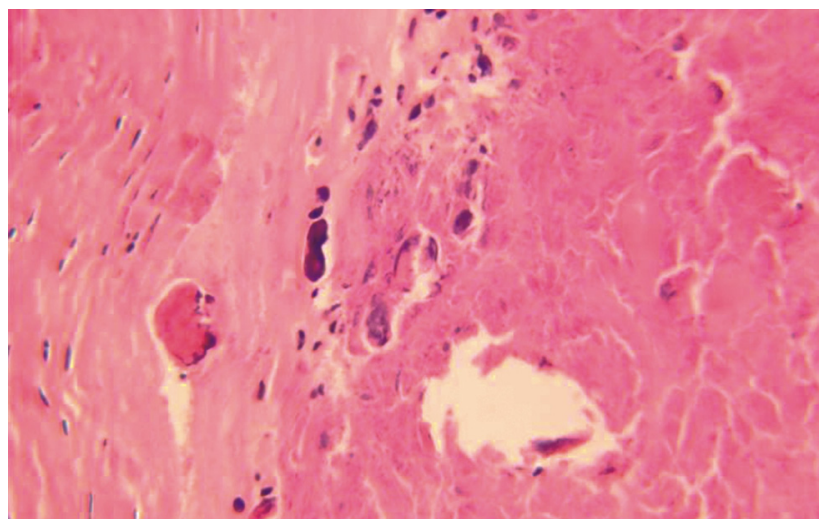

Fig. 2. Histopathologic examination of biopsied material shows fibrous collagenesis with granular calcification (H\&E stain X200).

scan 5 months after surgical resection confirmed no recurrence; at that time, symptoms continued to be almost completely relieved.

\section{Case 2}

A 67-year-old female patient presented with a two-month history of radiculopathy on the L3 dermatome of the right leg. She had undergone posterior cement-augmented pedicle screw fixation from T12 to L2 for burst fracture of L1 before 4 years. CT scans of the thoracolumbar spine showed a prominent central to right side calcified epidural mass measuring $10.4 \times 7.5 \mathrm{~mm}$, with a distinct increased density at the body of L2 and L3 (Fig. 3). Laminectomy of L2 and L3 and total removal of the epidural mass were done. After mass resection, extension of previous posterior fixation to L3 level was done. Pathology finding indicated CPN. Symptoms were resolved after surgical resection.

\section{Case 3}

A 78-year-old woman presented with a two-month history of low back pain after a slip. She had already been diagnosed as an osteoporotic compression fracture of L1 and had been treated conservatively. The pain had become worse over time. CT scan of the lumbar spine revealed a lobulated, calcified mass measuring $7 \times 8.5 \mathrm{~mm}$, with a well-defined margin along the left anterolateral side of the spinal canal at the L1 body level (Fig. 4). Left hemilaminectomy of L1 and epidural mass excision was done. Post-operatively, pain was resolved.

\section{DISCUSSION}

$\mathrm{CPN}$ or fibro-osseous lesions of the spine have been docu-

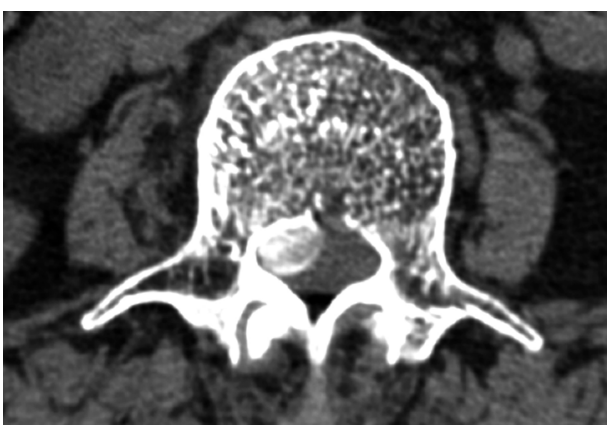

Fig. 3. Non-enhancing spinal computed tomography shows an epidural round mass located adjacent to the right anterolateral aspect of the spinal cord.

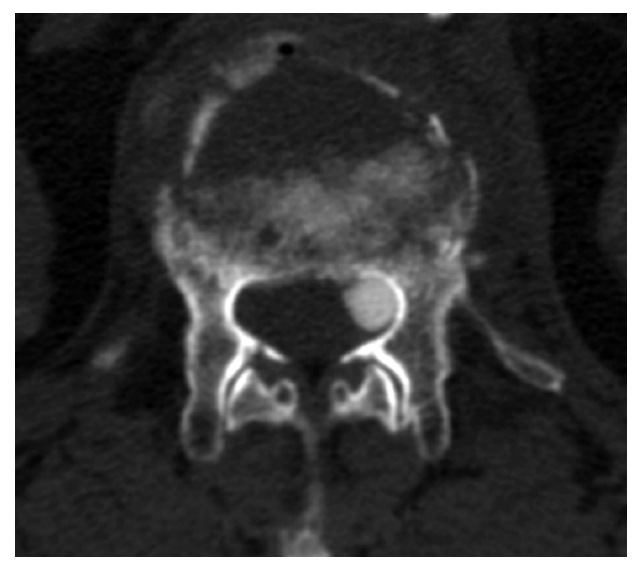

Fig. 4. Non-enhancing spinal computed tomography shows an oval mass at the left anterolateral side of the epidural space of the spine.

mented and reported in the literature in 27 cases, including these present three cases (Table 1$)^{2-5,7-15,17-19)}$. The age of the affected individuals has varied widely, from a 22-month-old girl to a 78-year-old woman. Half of cases occurred in middleage adults, with male patients predominating. No CPN has been described in the spinal intramedullary area.

Nine (33\%) of the 27 cases were cervical lesions and six (22\%) were located in the thoracic level. Lesions occurred in the lumbar spine in $12(44 \%)$ patients, with symptoms varying from axial back pain to radiculopathy.

Pathologic findings have revealed five histological features ${ }^{1)}$ : (1) chondromyxoid matrix in a nodular pattern, (2) palisading spindle to epithelioid cells, (3) fibrous stroma, (4) calcification, osseous metaplasia, or scattered psammoma bodies, and (5) foreign body type reaction with giant cell. These components vary markedly from patient to patient; the present three cases displayed some of these features.

The most common symptom of CPN is isolated pain. Radiculopathy due to compression of the nerve root is also common. For cervical lesions, myelopathy is the more frequent 
Table 1. Literature review of calcifying pseudoneoplasm in the spine

\begin{tabular}{|c|c|c|c|c|c|}
\hline No. of cases & Literature & Age (years) & Sex & Lesion & Symptom \\
\hline 1 & Bertoni et al, $1990^{* 3)}$ & 23 & $M$ & $\mathrm{T10}$ & back pain \\
\hline 2 & & 58 & $M$ & $\mathrm{C} 2-3$ & pain \\
\hline 3 & & 12 & $M$ & C6 & pain \\
\hline 4 & & 32 & $M$ & $\llcorner 4-5$ & back pain \\
\hline 5 & & 33 & $\mathrm{~F}$ & T9 & back pain \\
\hline 6 & & 68 & $\mathrm{~F}$ & $\llcorner 4-5$ & hip pain \\
\hline 7 & & 20 & $\mathrm{~F}$ & $\mathrm{C} 2$ & asymptomatic \\
\hline 8 & & 56 & $\mathrm{~F}$ & $\llcorner 4-5$ & back pain \\
\hline 9 & Smith \& Berry, 1994 ${ }^{18)}$ & 48 & $M$ & L2-3 & leg pain \\
\hline 10 & Moser et al., $1994^{11)}$ & 68 & $M$ & $\mathrm{C7}$ & arm pain \\
\hline 11 & Qian et al., 1999*15) & 59 & $M$ & $\mathrm{Cl}-2$ & myelopathy \\
\hline 12 & Mayr et al., $2000^{10)}$ & 58 & $M$ & T10-12 & myelopathy \\
\hline 13 & & 63 & $M$ & C3 & myelopathy \\
\hline 14 & Chang et al., 20004) & 60 & $M$ & $\mathrm{C} 2$ & neck pain \\
\hline 15 & Liccardo et al, $2003^{91}$ & 40 & $M$ & Т8-Т9 & myelopathy \\
\hline 16 & Park et al., $2008^{14)}$ & 59 & $\mathrm{~F}$ & C7-T1 & arm pain \\
\hline 17 & Tong et al., 2010 & 67 & $\mathrm{~F}$ & $\llcorner 4-5$ & back pain \\
\hline 18 & Rulseh et al, 2011 ${ }^{* 17)}$ & 43 & $M$ & L3 & back pain \\
\hline 19 & Kwan et al, 2012 & 48 & $M$ & T9 & chest pain \\
\hline 20 & Jentoft et al, 2012 & 26 & $\mathrm{~F}$ & L1 -2 & back pain \\
\hline 21 & Naidu et al, $2012^{13)}$ & 43 & $M$ & L4 & back pain \\
\hline 22 & Muccio ef al, 2012 ${ }^{* 12)}$ & 57 & $M$ & T10-11 & thoracic pain \\
\hline 23 & Bartanusz et al, 2013 & 1.83 & $\mathrm{~F}$ & $\mathrm{Cl}-2$ & neck pain \\
\hline 24 & Kocovski et el, $2015^{* 7)}$ & 64 & $\mathrm{~F}$ & L5 & back pain \\
\hline 25 & Present case & 77 & $\mathrm{~F}$ & $\mathrm{~T} 12$ & leg pain \\
\hline 26 & & 67 & $\mathrm{~F}$ & L2-3 & leg pain \\
\hline 27 & & 78 & $\mathrm{~F}$ & $\mathrm{~L} 1$ & back pain \\
\hline
\end{tabular}

Case series also included patients with cranial involvement.

symptom. However, an asymptomatic incidental mass has been reported $^{3)}$.

The radiologic manifestations of spinal CPN vary, although many cases feature hypointensity signal on T1- and T2-weighted MRI. Contrast enhancement on T1-weighted images has revealed no enhancement in some cases, with other cases displaying peripheral rim enhancement. Heterogeneous enhancement and internal linear enhancement have also been reported. Dense calcification is a characteristic of CT scans. Differential diagnosis for a calcified mass on the spinal cord include calcified disc material ${ }^{20)}$ or synovial cyst, psammomatous meningioma, epidural abscess, chronic hematoma, and infectious mass (e.g. tuberculoma).

The pathogenesis of CPN is still unclear. Garen et al. ${ }^{5)}$ postulated that the process may be an erroneous membranous bone formation with osseous metaplasia. Bertoni et al. ${ }^{3)}$ presumed that the cause of mass formation was unexpected expre- ssion of tumoural calcification in periarticular soft tissue. CPN is regarded as a being associated with degenerative joint disease. However, this view cannot explain cases of adolescents in whom joint degeneration was absent. Some cases occurred after trauma or surgery ${ }^{1,17)}$, bolstering the view that pathogenesis is associated with a reactive and metaplastic response to injury. In our three cases, CPN also presented after compression fracture trauma or following surgery. So, there may indeed be a relationship between CPN and tissue injury. The presence of granulomatous inflammation surrounding nodules of calcification substantiates this theory.

Most cases of spinal CPN have been treated with surgical management. Surgical total or subtotal resection of CPN has a good prognosis. Almost all patients experienced improvement of symptoms and very low rates of recurrence. Kwan et al ${ }^{8}{ }^{8}$ reported thoracic CPN in a 48 -year-old man, which resolved symptomatically and on imaging after treatment with 
oral indomethacin $25 \mathrm{mg} 3$ times daily. The lesion was seen to decrease in size on CT and MRI after 8 weeks of treatment and to completely resolve by 16 weeks of treatment.

\section{CONCLUSION}

Calcifying pseudoneoplasm of the spine is a very rare and benign entity. It causes variable nonspecific symptoms from pain to myelopathy. A dense calcified mass on extradural space post-trauma or following surgery should prompt consideration of CPN. Surgical excision of the lesion provides excellent prognosis, with the chance of recurrence being low.

\section{REFERENCES}

1. Aiken AH, Akgun H, Tihan T, Barbaro N, Glastonbury C: Calcifying pseudoneoplasms of the neuraxis: CT, MR imaging, and histologic features. Am J Neuroradiol 30:1256-1260, 2009

2. Bartanusz V, Ziu M, Jimenez DF, Henry JM: Calcifying pseudoneoplasm of the atlantoaxial joint in a child. J Neurosurg Spine 18:367-371, 2013

3. Bertoni F, Unni KK, Dahlin DC, Beabout JW, Onofrio BM: Calcifying pseudoneoplasms of the neural axis. J Neurosurg 72: 42-48, 1990

4. Chang H, Park JB, Kim KW: Intraosseous calcifying pseudotumor of the axis: A case report. Spine (Phila Pa 1976) 25:10361039, 2000

5. Garen PD, Powers JM, King JS, Perot PL Jr: Intracranial fibroosseous lesion. Case report. J Neurosurg 70:475-477, 1989

6. Jentoft ME, Scheithauer BW, Bertoni F, Abood C, Chang HT: Calcifying pseudoneoplasm of the neuraxis with single nerve rootlet involvement. Can J Neurol Sci 39:840-842, 2012

7. Kocovski L, Parasu N, Provias JP, Popovic S: Radiologic and histopathologic features of calcifying pseudoneoplasm of the neural axis. Can Assoc Radiol J 66:108-114, 2015

8. Kwan MK, Abdelhai AM, Saw LB, Chan CY: Symptomatic calcifying pseudotumor of the thoracic spine that resolved with the indomethacin treatment: A case report. Spine (Phila Pa 1976) 37:E1676-1679, 2012

9. Liccardo G, Lunardi P, Menniti A, Floris R, Pastore FS, Fraioli B: Calcifying pseudo-tumor of the spine: Description of a case and review of the literature. Eur Spine J 12:548-551, 2003

10. Mayr MT, Hunter S, Erwood SC, Haid RW Jr: Calcifying pseudoneoplasms of the spine with myelopathy. Report of two cases. J Neurosurg 93:291-293, 2000

11. Moser FG, Tourje EJ, Pressman BD, Blinderman EE: Calcifying pseudotumor of the cervical spine. Am J Neuroradiol 15:580, 1994

12. Muccio CF, Cerase A, Leone A, Dalena AM, Di Blasi A, De Simone $\mathrm{M}$, et al: Calcifying pseudoneoplasm of the neuraxis. Two case reports and review of CT and MR findings. Neuroradiol J 25:453-459, 2012

13. Naidu PK, Patel SC: Calcifying pseudoneoplasm of the neural axis arising within the lumbar spine: Implications of unique crosssectional imaging characteristics of a rare spinal column lesion. Neurographics 2:27-30, 2012

14. Park P, Schmidt LA, Shah GV, Tran NK, Gandhi D, La Marca F: Calcifying pseudoneoplasm of the spine. Clin Neurol Neurosurg 110:392-395, 2008

15. Qian J, Rubio A, Powers JM, Rosenblum MK, Pilcher WH, Shrier DA, et al: Fibro-osseous lesions of the central nervous system: Report of four cases and literature review. Am J Surg Pathol 23:1270-1275, 1999

16. Rhodes RH, Davis RL: An unusual fibro-osseous component in intracranial lesions. Hum Pathol 9:309-319, 1978

17. Rulseh AM, Keller J, Klener J, Šroubek J, Syrůček M, Zemanova I, et al: Calcifying pseudoneoplasms of the neural axis. Report of three cases. Cesk Neurol Neurochir 74:584-589, 2011

18. Smith DM, Berry AD 3rd: Unusual fibro-osseous lesion of the spinal cord with positive staining for glial fibrillary acidic protein and radiological progression: A case report. Hum Pathol 25:835-838, 1994

19. Tong D, Karunaratne N, Howe G, Spencer D, Manolios N: Clinical images: Calcifying pseudoneoplasm of the neuraxis. Arthritis Rheum 62:704, 2010

20. Yoo YS, Ju CI, Kim SW, Kim DM: Posterior epidural migration of an extruded lumbar disc mimicking a facet cyst: a case report. Korean J Spine 12:12-14, 2015 